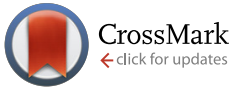

Cite this: Med. Chem. Commun., $2015,6,1513$

Received 12th April 2015, Accepted 16th June 2015

DOI: $10.1039 / c 5 m d 00151 j$

www.rsc.org/medchemcomm

\section{PPAR $\alpha$ agonists based on stilbene and its bioisosteres: biological evaluation and docking studies $\uparrow$}

\author{
Barbara De Filippis, ${ }^{*}$ Mariangela Agamennone, Alessandra Ammazzalorso, \\ Isabella Bruno, Alessandra D'Angelo, Mauro Di Matteo, Marialuigia Fantacuzzi, \\ Letizia Giampietro, Antonella Giancristofaro, Cristina Maccallini and Rosa Amoroso*
}

\begin{abstract}
A new series of gemfibrozil analogues conjugated with trans-stilbene were synthesized and evaluated with the aim of developing new PPAR $\alpha$ agonists. The phenyls of stilbene were modified by introducing substituents in the ortho or para position and only the distal ring was substituted with naphthyl or heteroaromatic moieties, keeping the dimethylpentanoic skeleton of gemfibrozil unaltered. Two compounds, $5 \mathrm{a}$ and $5 \mathrm{~d}$, exhibited good activation of PPAR $\alpha$ and were also screened for their activity on PPAR $\alpha$-regulated gene CPT1A. Structure-based studies carried out on the active ligands highlighted the dominant role of ligand solvation energy and hydrophobic effect in determining the PPAR $\alpha$ activation.
\end{abstract}

\section{Introduction}

Peroxisome Proliferator-Activated Receptors (PPARs) are transcription factors belonging to the nuclear receptor superfamily, whose members selectively bind lipophilic ligands and transduce chemical signals into specific changes in gene expression. PPAR is a compact molecule, consisting of four functional domains: $N$-terminal ligand-independent activation domain, DNA binding domain (DBD), co-FBD (site for cofactors coupling) or D domain and C-terminal ligand binding domain (LBD). The binding of PPAR with a ligand induces conformational changes which permit the interaction with Retinoid X Receptor (RXR), thus building an activated heterodimer capable of recognizing the DNA PPAR responsive elements (PPREs). In this process, the nuclear corepressors, often functioning as transcriptional repressors, are replaced with coactivators resulting in transcriptional activation. ${ }^{1}$

There are three PPAR isotypes, designed as PPAR $\alpha$, $\operatorname{PPAR} \beta / \delta$ and PPAR $\gamma$; they are a tightly connected triad and act as regulators of the intermediary metabolism of glucose and lipid homeostasis, adipogenesis, immune response, cell growth, and differentiation. ${ }^{2}$ Despite the high levels of homology at the protein level, the diversity of PPARs implies diverse distribution in body tissues and different ligand responses. Recently, the development of pan and selective ligands has greatly advanced the understanding of the

Dipartimento di Farmacia, Università degli Studi "G. d'Annunzio", via dei Vestini 31, 66100 Chieti, Italy

$\dagger$ Electronic supplementary information (ESI) available. See DOI: 10.1039/c5md00151j pathways controlled by PPARs and the therapeutic implications of modulating these receptors. ${ }^{3}$ The PPAR $\alpha$ isoform is highly expressed in the liver, heart, brown adipose tissue, skeletal muscle, and kidney; its activation by natural ligands, fatty acids (FA) and eicosanoids promotes mitochondrial FA oxidation and regulates lipid metabolism. Synthetic agonists of PPAR $\alpha$ are hypolipidemic drugs such as fibrates. ${ }^{4}$

$\operatorname{PPAR} \gamma$, expressed predominantly in adipose tissue, liver, and immune cells, plays crucial roles in fat and glucose metabolism, cell proliferation, differentiation, and apoptosis. $\operatorname{PPAR} \gamma$ agonists like thiazolidinediones are used to treat type 2 diabetes, thus improving insulin signaling and glucose uptake by adipose tissue. ${ }^{5} \operatorname{PPAR} \beta / \delta$ is the most widely expressed PPAR subtype, found in liver, skin and large and small intestines; however, the role of PPAR $\beta / \delta$ has been less explored. To date, there are no $\operatorname{PPAR} \beta / \delta$ drugs being marketed, but some ligands are currently in clinical trials for metabolic syndrome. ${ }^{6}$

As a part of the ongoing research to find an effective PPAR-target based drug candidate, we have recently reported PPAR agonists derived from the combination of the antilipidemic moiety of fibrate and natural $\alpha$-asarone, stilbene, chalcone, and other bioisosteric modifications. ${ }^{7}$ Good agonistic activity on PPAR $\alpha$ was seen with the trans-stilbene derivative (1) of gemfibrozil $\left(\mathrm{EC}_{50}=1.0 \mu \mathrm{M}\right)$. Starting from these studies, we achieved an initial SAR study by systematically varying the structural features of lead 1 to assess the contribution of various changes in the hydrophobic stilbene scaffold to the binding affinity. Particularly, we focused our attention on the distal phenyl group, since this moiety might be critical for the active conformation of PPAR $\alpha$ LBD. A 
suitable structural manipulation might influence the ability of the ligand-bound PPAR $\alpha$ to form a transcriptionally active conformation. By varying the nature of the para substituent of distal phenyl or by substituting it with a naphthyl, thiophene or pyridine ring, we sought to estimate the contribution of electronic, steric and hydrogen bonds to the binding affinity. Since the compound containing chlorine was the most active, we also explored the effect of additional chlorine atoms in the ortho positions of the two phenyls of stilbene (Fig. 1).

The in vitro transactivation assay was used to test the PPAR activation of the new compounds. Ligands with the best $\mathrm{EC}_{50}$ were also selected for the in vitro evaluation of CPT1A gene activation by real-time quantitative PCR (RTqPCR) analysis. To provide an explanation for the observed activity data, docking and post-docking calculations of the studied ligands on the PPAR $\alpha$ receptor were carried out, eliciting the most relevant energy contributions to the binding process.

\section{Results and discussion}

The reaction of 4-hydroxybenzaldehyde with the appropriate arylacetic acid ( $2 \mathbf{a}-\mathbf{1}$ and $\mathbf{2 n}-\mathbf{p})$ in the presence of piperidine, at $130{ }^{\circ} \mathrm{C}$, fournished the phenols $3 \mathrm{a}-\mathbf{l}$ and $\mathbf{3 n}-\mathbf{p} .{ }^{8}$ Phenol $3 \mathrm{~g}$ $\left(\mathrm{Ar}=p-\mathrm{NO}_{2} \mathrm{C}_{6} \mathrm{H}_{4}\right)$ was reduced to $p$-aminoderivative $3 \mathrm{~m}$ and the potassium salts of $3 \mathbf{a}-\mathbf{p}$, except $\mathbf{3 g}$, were then reacted with commercially available isobutyl 5-chloro-2,2dimethylpentanoate, in refluxing DMF, to give the esters $4 a-f$ and $4 \mathbf{h}-\mathbf{p}$. Ester $4 \mathrm{~g}$ showed instability in these reaction conditions thus it has not been possible to synthesize the corresponding acid. The acids $\mathbf{5 a - f}$ and $\mathbf{5 h}-\mathbf{p}$ were finally obtained by hydrolysis of $\mathbf{4 a}-\mathbf{f}$ and $4 \mathbf{h}-\mathbf{p}$ in the presence of $\mathrm{NaOH}$ in EtOH (Scheme 1).

In order to evaluate PPAR $\alpha$ agonistic potency and subtype selectivity, we performed an in vitro screening of the new compounds in a cell-based transactivation assay in eukaryotic cells $;^{9}$ our reporter system utilizes firefly luciferase reporter

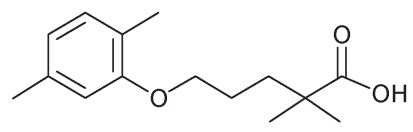

Gemfibrozil

Replacement of phenyl with other aromatic rings

$0, p$-Substitution

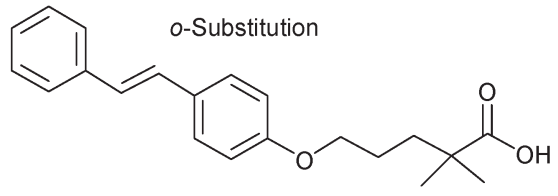

1

Fig. 1 Gemfibrozil, compound 1 and chemical modifications. gene technology to provide optimal assay sensitivity, dynamic range when quantifying nuclear receptor activity, and good correlation with in vivo activity. ${ }^{10}$ Compounds $5 \mathbf{a}-\mathbf{f}$ and $5 \mathbf{h}-\mathbf{p}$ were evaluated for their agonist activity on the human $\operatorname{PPAR} \alpha, \operatorname{PPAR} \gamma$, and PPAR $\delta$ subtypes. The results obtained were compared with the corresponding data for gemfibrozil, rosiglitazone, and L-165,041, which were used as reference compounds in the PPAR $\alpha, \operatorname{PPAR} \gamma$, and $\operatorname{PPAR} \delta$ transactivation assays, respectively. As the first step, we evaluated the ability of the new compounds to activate PPAR at a concentration of $150 \mu \mathrm{M}$ and the results are expressed as efficacy $(E, \%)$, calculated as the percentage of the maximum obtained fold induction with the reference compounds, normalized to $100 \%$. On the basis of this preliminary study, compounds with $E$ (\%) higher than the reference compounds were selected for the determination of the $\mathrm{EC}_{50}$ values. The in vitro PPAR activity results are summarized in Table 1.

All compounds showed activation of PPAR $\alpha$, with good efficacy values, except $5 \mathrm{c}\left(p-\mathrm{iPrC}_{6} \mathrm{H}_{4}\right), 5 \mathrm{e}\left(p-\mathrm{CNC}_{6} \mathrm{H}_{4}\right)$, and $5 \mathrm{~m}$ $\left(p-\mathrm{NH}_{2} \mathrm{C}_{6} \mathrm{H}_{4}\right)$, which were inactive. Good efficacies on PPAR $\alpha$ were achieved with derivatives $5 \mathbf{a}\left(p-\mathrm{ClC}_{6} \mathrm{H}_{4}\right)$ and $\mathbf{5 d}(p$ $\mathrm{CF}_{3} \mathrm{C}_{6} \mathrm{H}_{4}$ ), which exhibited values 2 fold of gemfibrozil, comparable with stilbene derivative 1 . Compounds $5 \mathbf{b}(p$ $\left.\mathrm{MeC}_{6} \mathrm{H}_{4}\right), 5 \mathbf{f}\left(p-\mathrm{OMeC}_{6} \mathrm{H}_{4}\right), 5 \mathbf{h}$ (naphthyl), 5i (thienyl), and $5 \mathbf{l}$ (pyridinyl) showed PPAR $\alpha$ affinity comparable to gemfibrozil and lower than stilbene derivative 1 . Based on the above results, compounds $5 \mathbf{a}, \mathbf{5 b}, \mathbf{5 d}, \mathbf{5 f}, \mathbf{5 h}, \mathbf{5 i}$, and $5 \mathbf{l}$ were subjected to $\mathrm{EC}_{50}$ determination. The best results were obtained with 5a and 5d, which contain the electronwithdrawing substituents $\mathrm{Cl}$ and $\mathrm{CF}_{3}$; they showed approximately the same potency towards $\operatorname{PPAR} \alpha\left(\mathrm{EC}_{50} 0.8 \mu \mathrm{M}\right.$ and $0.7 \mu \mathrm{M}$, respectively) as compared to $1\left(\mathrm{EC}_{50} 1.0 \mu \mathrm{M}\right)$, and were more active than gemfibrozil. Compounds $\mathbf{5 b}$ and $\mathbf{5 i}$ showed improved agonistic activity $\left(\mathrm{EC}_{50} 3.3 \mu \mathrm{M}\right.$ and $3.8 \mu \mathrm{M}$, respectively) compared to gemfibrozil, but were found to be less active as compared to unsubstitued stilbene $\mathbf{1}$. At last, $\mathbf{5 f}$, $\mathbf{5 h}$, and $\mathbf{5 l}$ showed a decrease in PPAR $\alpha$ activity as compared to the parent compound 1 , even worse than gemfibrozil. PPAR $\alpha$ seems to be able to accommodate the different substituents without greatly affecting the activity except for ana$\log$ 50-p which show very low activity. The insertion of a chlorine atom in the ortho position of the proximal aromatic ring caused a drastic reduction in activity on PPAR $\alpha$ ( $5 n$ and 5p vs. 5a) as well as the introduction of a second chlorine atom in the ortho position of the proximal one. These results showed that the effect of the substitution pattern of the aromatic moiety on the binding affinity is strongly dependent on the respective substituent, indicating that the effect of different substitutions on the binding affinity towards the PPAR $\alpha$-LBD is not merely additive. At last, none of the tested compounds was able to exhibit full agonist activity on PPAR $\gamma$ and PPAR $\delta$, showing lower potency than rosiglitazone and L-165,041, regardless of the substituent introduced on stilbene.

On the basis of these results, we decided to confirm the capability of $\mathbf{5 a}$ and $\mathbf{5 d}$ (with the best $\mathrm{EC}_{50}$ values) to act as 


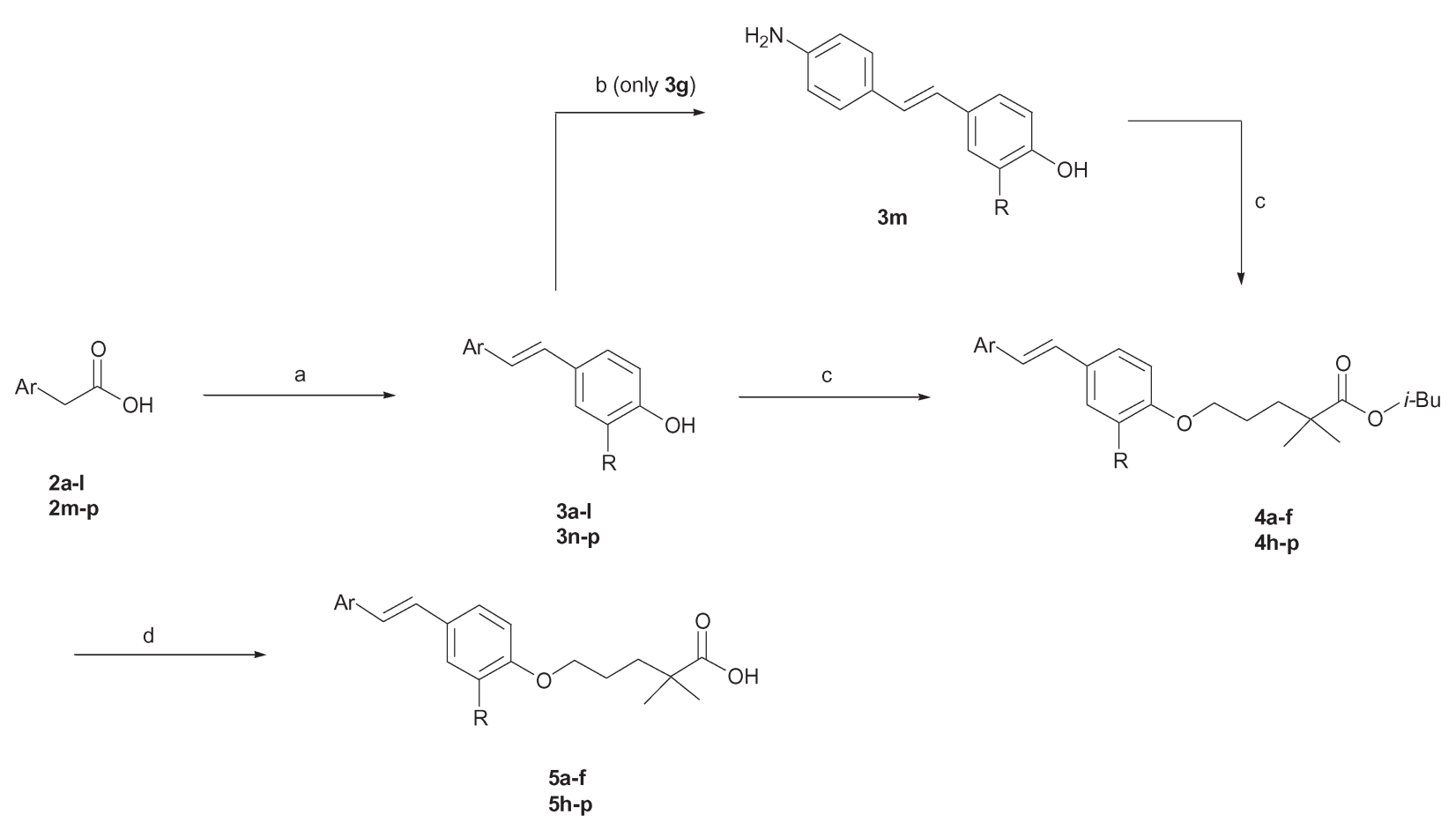

Scheme 1 Reagents and conditions: (a) 4-hydroxybenzaldehyde, piperidine, $130{ }^{\circ} \mathrm{C}, 4-24 \mathrm{~h}$; (b) $\mathrm{SnCl}_{2}, \mathrm{EtOH}, \mathrm{HCl}, \mathrm{reflux}, 3.5 \mathrm{~h}$; (c) isobutyl 5-chloro-2,2-dimethylpentanoate, $\mathrm{K}_{2} \mathrm{CO}_{3}$, DMF, reflux, 5-12 h; (d) $\mathrm{NaOH} 1 \%$, EtOH, reflux, 8-12 h.

Table 1 In vitro PPAR transactivation of test and reference compounds

\begin{tabular}{|c|c|c|c|c|c|c|}
\hline \multirow[b]{2}{*}{ Compound } & \multirow[b]{2}{*}{$\mathrm{Ar}$} & \multirow[b]{2}{*}{$\mathbf{R}$} & \multicolumn{2}{|l|}{ PPAR $\alpha$} & \multirow{2}{*}{$\frac{\text { PPAR } \gamma}{E(\%)}$} & \multirow{2}{*}{$\frac{\text { PPAR } \delta}{E(\%)}$} \\
\hline & & & $E^{a}(\%)$ & $\mathrm{EC}_{50}(\mu \mathrm{M})^{b}$ & & \\
\hline $5 \mathbf{a}$ & $p-\mathrm{ClC}_{6} \mathrm{H}_{4}$ & $\mathrm{H}$ & 227 & $0.8 \pm 0.07$ & 25 & 20 \\
\hline $5 c$ & $p$-i-PrC ${ }_{6} \mathrm{H}_{4}$ & $\mathbf{H}$ & 17 & $-^{c}$ & 38 & 42 \\
\hline $5 d$ & $p-\mathrm{CF}_{3} \mathrm{C}_{6} \mathrm{H}_{4}$ & $\mathrm{H}$ & 205 & $0.76 \pm 0.02$ & 55 & 40 \\
\hline $5 e$ & $p-\mathrm{CNC}_{6} \mathrm{H}_{4}$ & $\mathrm{H}$ & 23 & - & 89 & 36 \\
\hline $5 i$ & Thienyl & $\mathrm{H}$ & 152 & $3.8 \pm 0.15$ & 78 & 17 \\
\hline 51 & Pyridinyl & $\mathrm{H}$ & 115 & $103.2 \pm 1.15$ & 42 & 39 \\
\hline $5 \mathrm{~m}$ & $p-\mathrm{NH}_{2} \mathrm{C}_{6} \mathrm{H}_{4}$ & $\mathrm{H}$ & 29 & - & 54 & 59 \\
\hline $5 n$ & $\mathrm{C}_{6} \mathrm{H}_{5}$ & $\mathrm{Cl}$ & 46 & - & 44 & 40 \\
\hline 50 & $o, p-\mathrm{ClC}_{6} \mathrm{H}_{4}$ & $\mathbf{H}$ & 32 & - & 30 & 60 \\
\hline $5 p$ & $o, p-\mathrm{ClC}_{6} \mathrm{H}_{4}$ & $\mathrm{Cl}$ & 20 & - & 18 & 12 \\
\hline 1 & & & 223 & $1.0 \pm 0.02$ & 25 & 17 \\
\hline
\end{tabular}

${ }^{a} E(\%)$, efficacy values calculated as percentage of the maximum obtained fold induction with the reference compounds (gemfibrozil for PPAR $\alpha$, rosiglitazone $\left(\mathrm{EC}_{50} 0.039 \pm 0.003 \mu \mathrm{M}\right)$ for PPAR $\gamma$, and $\mathrm{L}-165,041\left(\mathrm{EC}_{50} 0.021 \pm 0.001 \mu \mathrm{M}\right)$ for PPAR $\delta$ ); compounds were tested in at least three separate experiments at $150 \mu \mathrm{M}$. The results are expressed as mean \pm SEM. ${ }^{b}$ Compounds were tested in at least three separate experiments at five concentrations ranging from 1 to $150 \mu \mathrm{M}$. The results are expressed as mean \pm SEM. ${ }^{c}$ Not determined.

PPAR $\alpha$ ligands by conducting gene expression experiments in HepG2 cells, which express PPAR $\alpha$, and the results were compared with those obtained from gemfibrozil. The enzyme carnitine palmitoyltransferase 1A (CPT1A) catalyzes the longchain fatty acid translocation into the mitochondrial matrix, an essential step for $\beta$-oxidation in the liver, ${ }^{11}$ and PPAR $\alpha$ is known to up-regulate CPT1A expression through ligand- dependent transcriptional activation. For this reason, the expression pattern of CPT1A is a well established in vitro model to study PPAR $\alpha$ activation. ${ }^{12}$ The human hepatocellular carcinoma cell line HepG2 was used to analyze the impact of $5 \mathbf{a}$ and $5 \mathbf{d}$ on PPAR $\alpha$ expression; measurement of mRNA concentration was done as a quantitative analysis by RTqPCR. HepG2 cells were stimulated with increasing 
amounts of selected compounds (from 1 to $100 \mu \mathrm{M}$ ) and compared with gemfibrozil and $\mathbf{1}$ at $\mathrm{EC}_{50}$ concentration; control cells were treated with only DMSO. The stimulation of HepG2 cells with gemfibrozil showed a slight increase of mRNA levels, while incubation of cells with increasing amounts of 1 led to a significant and concentrationdependent increase of mRNA levels; indeed, at an intermediate concentration of $10 \mu \mathrm{M}$, the mRNA induction was doubled with respect to gemfibrozil and at $100 \mu \mathrm{M}$ the relative mRNA was about 6.0 (Fig. 2).

Compounds 5a and 5d did not affect the expression of CPT1A gene in the same manner as $\mathbf{1}$, even if a dosedependent activation of gene expression was observed for both compounds. At a maximum concentration of $100 \mu \mathrm{M}$, the mRNA induction for $\mathbf{5 a}$ and $\mathbf{5 d}$ was approximately doubled with respect to gemfibrozil; moreover, compound 5d also showed a value of induction greater than gemfibrozil at an intermediate concentration of $10 \mu \mathrm{M}$.

Docking calculations on PPAR $\alpha$-LBD were carried out to gain more insight into their putative binding mode. All stilbene derivatives, in the deprotonated form, were docked in the crystal structure of PPAR $\alpha$ with PDB ID: 2P54 (details of the docking protocol are reported in the ESI $\dagger$ ). This X-ray structure was chosen among available crystallographic complexes because of its good resolution (1.79 $)$ ) and the structural similarity between the co-crystallized ligand and the studied compounds. Glide's ${ }^{13}$ docking protocol was validated by the reproduction of the crystallographic pose of X-ray ligands. This preliminary analysis allowed us to evaluate the ability of the receptor structure to correctly reproduce the X-ray ligands' binding mode.

To further assess the reliability of our model, docked poses of each ligand were subjected to a post-docking refinement using the MM-GBSA module in Prime. This approach minimizes docked complexes, allowing a more accurate calculation of the binding energy. Energy contributions calculated by this method were used to build a customized scoring

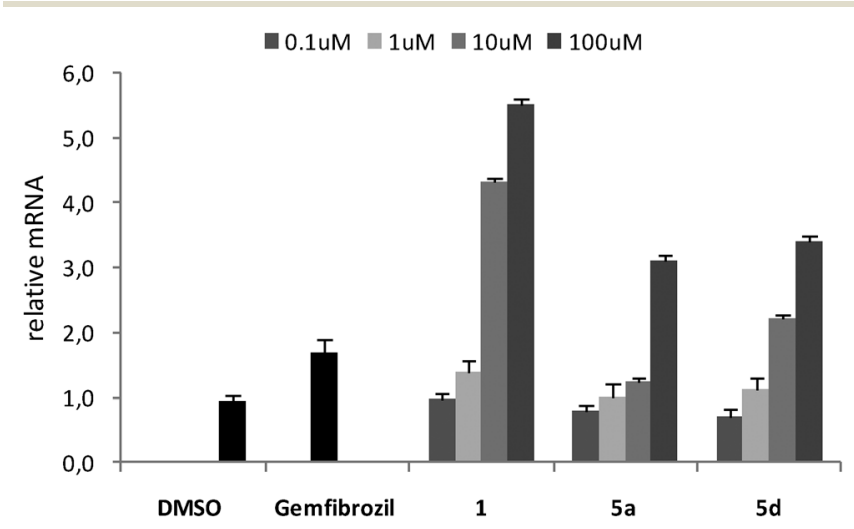

Fig. 2 CPT1A expression in HepG2 cells after treatment. RTqPCR was performed to measure the CPT1A mRNA levels. Values shown represent the mean \pm SEM of four independent determinations performed in duplicate. Cyclophilin was used as reference gene, and values were normalized to the data obtained from vehicle treated cells. function (1) that allowed the correlation of the computational and experimental $\mathrm{EC}_{50}$ for the active ligands. To this aim, a multiple linear regression approach was applied to generate a model with good statistical parameters $\left(R^{2}=0.98\right.$, Std Dev $=0.13, q_{\text {loo }}^{2}=0.96, F=109.2, P=2.72 \times 10^{-4}$ ), underpinning the reliability of the predicted docking poses (Fig. 3).

It is worth noting that the $\mathrm{pEC}_{50}$ values come from a cellbased assay evaluating the activation of $\operatorname{PPAR} \alpha$, and is not directly related to the binding of the ligands to the receptor. However, as exhaustively explained by Lannutti et al., ${ }^{14} \mathrm{pEC}_{50}$ and binding $\Delta G$ can be considered linearly related.

$$
\begin{aligned}
\mathrm{pEC}_{50}= & 2.96+10^{1}+\left(9.72 \times 10^{-1} \times \text { Ligand Solv GB }\right) \\
& +\left(4.32 \times 10^{-2} \times \text { Rec Strain Lipo }\right) \\
& -\left(2.04 \times 10^{-1} \times \text { Rec Strain SelfCont }\right)
\end{aligned}
$$

The analysis of energy parameters mostly contributing to the ligand potency showed the relevant role of ligand solvation energy (Ligand Solv GB). Interestingly, by evaluating a single correlation with separate parameters, we found that Ligand Solv GB has a strong correlation with $\mathrm{pEC}_{50}\left(R^{2}=\right.$ 0.89 ), contributing significantly to discriminate the relative binding energy and indicating that the ligand affinity is predominantly influenced by the desolvation effect of the active ligands. Besides this aspect, the ligand binding effect on the receptor also plays a relevant role, in particular due to improved hydrophobic contacts (Rec Strain Lipo) and the conformational rearrangement affecting the receptor residue self-contacts (Rec Strain SelfCon). The accurate structurebased protocol, applied to all active stilbene derivatives, afforded docked poses very close to that of the co-crystallized ligand, occupying the L-shaped PPAR $\alpha$ pocket. Putative binding poses of the representative compound $\mathbf{5 d}$ are stabilized by a combination of $\mathrm{H}$-bonds and hydrophobic interactions (Fig. 4).

The carboxylate group forms the well-recognized H-bond network with Ser280 (H3), Tyr314 (H5), His440 (H11), and Tyr464 (AF2 helix), the latter being essential for the recruitment of co-activators. The remaining interactions between

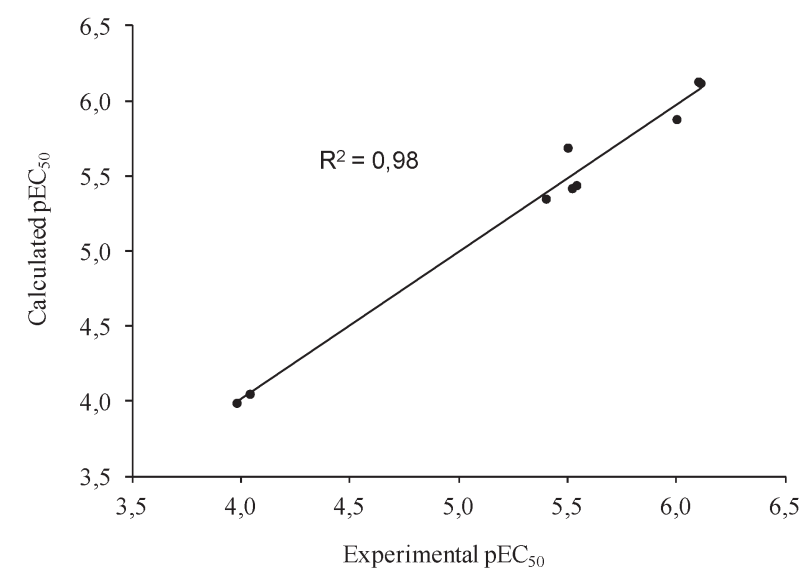

Fig. 3 The predicted versus experimental $\mathrm{pEC}_{50}$ values for the activation of PPAR $\alpha$. 


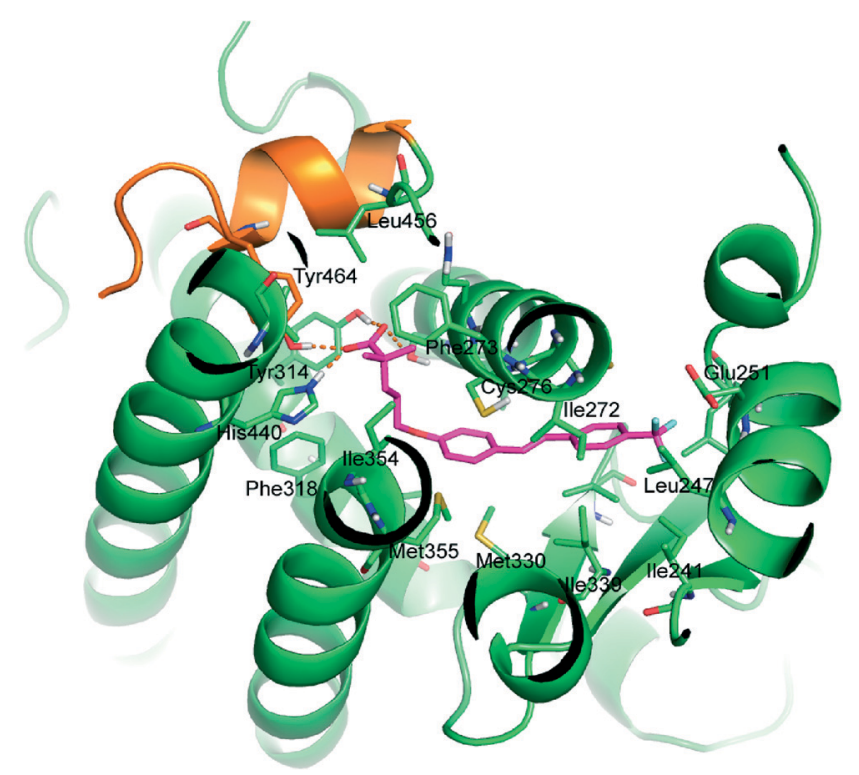

Fig. 4 Binding mode of $5 d$ (magenta $C$ atoms) in the PPAR $\alpha$ biding site represented as green cartoon. AF2 helix is reported as an orange cartoon. Interacting residues are represented as sticks. Carboxylate $\mathrm{H}$-bonds are reported as orange dashed lines.

ligands and protein are hydrophobic: the two methyl substituents in $\alpha$ provide positive contacts with Phe273, Val444, Leu456, Gln277, Ile354, and Cys276. The alkyl chain forms good interactions with Phe318, Ile354, His440, and Cys276. The stilbene function interacts with Leu231, Met330, Cys276, Ile272, Cys275, Leu247, Ile339, Val332, Thr279, Met355, Met330, and Leu321. The substituent in the para position, responsible for the different activities among the studied analogues, occupies the bottom of the hydrophobic pocket and engages in favourable lipophilic interactions with Ile241, Leu254, Leu247, and C $\gamma$ of Glu251.

\section{Conclusions}

In this paper new gemfibrozil analogues conjugated with trans-stilbene were synthesized and evaluated as PPAR agonists. Stilbene was modified by introducing various substituents on the two aromatic rings or replacing the distal phenyl with naphthyl or heteroaromatic moieties, keeping the dimethylpentanoic skeleton of gemfibrozil unaltered. Two compounds, $5 \mathbf{a}$ and $\mathbf{5 d}$, exhibited good activation of PPAR $\alpha$ at submicromolar concentration, selectivity towards PPAR $\gamma$ and $\beta / \delta$ and a dose dependent activation of PPAR $\alpha$ target gene CPT1A, and were also screened for their activity on PPAR $\alpha$-regulated gene CPT1A. Considering the degree of the isoform selectivity displayed by these compounds, we identified new ligands with good potency on PPAR $\alpha$, but low potency and partial agonism on PPAR $\gamma$ and PPAR $\delta$. Moreover, structure-based studies carried out on the active ligands highlighted the dominant role of the ligand solvation energy and the hydrophobic effect in determining the PPAR $\alpha$ activation.

\section{Acknowledgements}

The authors gratefully acknowledge the University "G. d'Annunzio" of Chieti for financial support and Prof. Antonio Moschetta (University of Bari, Italy) for his helpful comments and suggestions.

\section{References}

1 (a) B. P. Kota, T. H. Huang and B. D. Roufogalis, Pharmacol. Res., 2005, 51, 85; (b) J. Berger and D. E. Moller, Annu. Rev. Med., 2002, 53, 409.

2 (a) M. Moreno, A. Lombardi, E. Silvestri, R. Senese, F. Cioffi, F. Goglia, A. Lanni and P. de Lange, PPAR Res., 2010, 435689; (b) T. Li and J. Y. L. Chiang, PPAR Res., 2009, 501739; (c) L. la Cour Poulsen, M. Siersbæk and S. Mandrup, Semin. Cell Dev. Biol., 2012, 23, 631.

3 (a) C. Pirat, A. Farce, N. Lebègue, N. Renault, C. Furman, R. Millet, S. Yous, S. Speca, P. Berthelot, P. Desreumaux and P. Chavatte, J. Med. Chem., 2012, 55, 4027; (b) P. L. Feldman, M. H. Lambert and B. R. Henke, Curr. Top. Med. Chem., 2008, 8, 728; (c) A. Ammazzalorso, B. De Filippis, L. Giampietro and R. Amoroso, ChemMedChem, 2013, 10, 1609.

4 (a) J. C. Fruchart, Atherosclerosis, 2009, 205, 1; (b) B. Staels, M. Maes and A. Zambon, Nat. Clin. Pract. Cardiovasc. Med., 2008, 5, 542 .

5 (a) M. Ahmadian, J. Myoung Suh, N. Hah, C. Liddle, A. R. Atkins, M. Downes and R. M. Evans, Nat. Med., 2013, 99, 557; (b) B. Cariou, B. Charbonnel and B. Staels, Trends Endocrinol. Metab., 2012, 23, 205.

6 (a) K.-D. Wagner and N. Wagner, Pharmacol. Ther., 2010, 125, 423; (b) L. S. Mackenzie and L. Lione, Life Sci., 2013, 93, 963.

7 (a) B. De Filippis, A. Giancristofaro, A. Ammazzalorso, A. D'Angelo, M. Fantacuzzi, L. Giampietro, C. Maccallini, M. Petruzzelli and R. Amoroso, Eur. J. Med. Chem., 2011, 46, 5218; (b) B. De Filippis, P. Linciano, A. Ammazzalorso, C. Di Giovanni, M. Fantacuzzi, L. Giampietro, A. Laghezza, C. Maccallini, P. Tortorella, A. Lavecchia, F. Loiodice and R. Amoroso, Eur. J. Med. Chem., 2015, 89, 817.

8 (a) E. S. Lazer, H. C. Wong, G. J. Possanza, A. G. Graham and P. R. Farina, J. Med. Chem., 1990, 33, 1892; (b) S. Hang, M. P. Oya, C. Kung, D. L. Hou, H. F. Maier and J. Kung, Med. Chem., 2005, 48, 5980.

9 I. G. Schulman and R. A. Heyman, Chem. Biol., 2009, 11, 639.

10 L. H. Naylor, Biochem. Pharmacol., 1999, 58, 749.

11 J. D. McGarry and N. F. Brown, Eur. J. Biochem., 1997, 244, 1.

12 J. W. Lawrence, Y. Li, S. Chen, J. G. De Luca, J. P. Berger, D. R. Umbenhauer, D. E. Moller and G. Zhou, J. Biol. Chem., 2001, 276, 31521.

13 Glide, version 5.8, Schrödinger, LLC, New York, NY, 2012.

14 F. Lannutti, A. Marrone and N. Re, J. Mol. Graphics Modell., 2011, 29, 865. 